\title{
SHORT- AND LONG-TERM EFFECTS OF NEONICOTINOID APPLICATION IN RICE FIELDS, ON THE MORTALITY AND COLONY COLLAPSE OF HONEYBEES (APIS MELLIFERA)
}

\author{
Takashi Matsumoto ${ }^{1,2 *}$ \\ ${ }^{1}$ Honey Bee Research Unit, NARO, National Institute of Livestock and \\ Grassland Science, Tsukuba, Japan, 305-0901 \\ Current address: School of Environmental Science, \\ The University of Shiga Prefecture, Hikone, Japan, 522-8533 \\ *corresponding author: taka4matu@gmail.com \\ Received 22 June 2012; accepted 10 July 2013
}

\begin{abstract}
Declines in honeybee (Apis mellifera) colonies have elicited great concern worldwide. Recently, many Japanese beekeepers have implied that midsummer use of a new insecticide, neonicotinoid, in rice fields, is causing widespread mortality of neighboring honeybees and frequently resulting in colony collapse. Since few field experiments have directly tested the effects of neonicotinoids, I addressed four research questions in the field. The questions are: 1) Does clothianidin application in rice fields cause the collapse of neighboring honeybee colonies? 2) Is colony collapse related to hive distance from the rice field? 3) Is the number of dead honeybee workers after spraying, related to hive distance from the field? 4) What are the long-term effects of neonicotinoid use on honeybee colony growth, especially brood production? In the late summer of 2010 , honeybee hives were placed adjacent to two separate rice fields for 1 week. The hives were placed at the distance of $0,30,60$, and $90 \mathrm{~m}$. After spraying clothianidin, a daily count of dead worker honeybees was done for a week. Hives were weighed, and capped-brood areas were estimated weekly, for 2 months following insecticide application. Although the average number of dead workers ranged from $\mathbf{4 0}$ to over 100 within 24 hours after spraying, only a few dead workers were observed in the subsequent days. Distance from the rice field had no significant effect on the number of dead workers. There were no collapsed colonies during the 2-month, post-spray observation period. Hive weight and capped-brood area did not significantly differ among those hives placed at varying distances from the rice field. These results indicated that clothianidin spraying of the rice field increased the mortality of the honeybees, but did not always cause colony collapse.
\end{abstract}

Keywords: Apis mellifera, clothianidin, honeybee, neonicotinoid, pesticide, rice field.

\section{INTRODUCTION}

Recent global declines in pollinator populations have raised considerable concern (Goulson et al., 2008). It is the pollinators that provide vital ecosystem services in natural terrestrial systems (Aguilar et al., 2006) and agricultural fields (Ricketts et al., 2008). Pollinators contribute to the maintenance of wild plant communities and enhanced crop production. The loss of pollinator diversity could potentially result in reductions of pollination services. The ecological and economic impacts are far-reaching. For example, reductions in pollinator populations have led to parallel declines in their plant mutualists (Biesmeijer et al., 2006). Pumpkin yields have decreased as well, due to the lack of pollinators in New York State (Watanabe, 1994). Bees are the primary pollinators of most agricultural crops and wild plants (Potts et al., 2010). The honeybee (Apis mellifera L.), in particular, has been used widely in agricultural systems. The honeybee also plays an important role within natural plant communities. In fact, the number of agricultural crops that depend on honeybees is increasing (Aizen et al., 2008). Similar to many pollinators, losses of managed honeybee colonies have been occurring worldwide (Biesmeijer et al., 2006; Pettis and Delaplane, 2010; Potts et al., 2010; 
VanEngelsdorp and Meixner, 2010). Agricultural pesticide use has been suggested as the primary cause of honeybee declines (Allen-Wardell et al., 1998; Oldroyd, 2007; Orantes-Bermejo et al., 2010). A new class of insecticides, neonicotinoids, has been implicated by beekeepers as posing a serious threat to honeybee populations. The area being treated with neonicotinoids is markedly increasing due to the pest control performance of neonicotinoids (Elbert et al., 2008). Neonicotinoids are systemic insecticides, thus their potential effects include not only acute toxicity of the adult honeybee workers by direct exposure, but also chronic toxicity from the potential exposure of broods to insecticide residue in pollen, nectar, and beeswax (Tasei et al., 2001; Abbott et al., 2008).

Consequently, many studies have examined the effects of neonicotinoids, but only a few have demonstrated any negative effects on honeybees under field conditions. For example, the concentration of neonicotinoids in guttation drops of corn seedlings was found to be higher than or similar to concentrations sprayed in the field (Girolami et al., 2009). When multiplying known toxic doses in pollen and nectar of maize and sunflower fields by the estimated amount consumed by honeybees, it can be determined that nurse bees were potentially exposed to lethal doses (Rortais et al., 2005). In addition, sublethal neonicotinoid exposure of honeybees can reduce the expected performance of the colony by $6-20 \%$ (Cresswell, 2011). However, the majority of studies have not found evidence that neonicotinoid plays a role in total honeybee loss. For example, several studies have reported neonicotinoid residue levels below either the lethal dose or the limit of detection (Schmuck et al., 2001; Bernal et al., 2010; Chauzat et al., 2010; Mullin et al., 2010). Chauzat et al. (2009) found no relationship between residue levels of pesticide in pollen or nectar and colony mortality. Nguyen et al. (2009) found that neonicotinoid spraying in a maize field was not significantly negatively related to honeybee colony performance. In feeding experiments, syrup or pollen laced with concentrations of neonicotinoids similar to those observed in the field, had no impact on colony growth (Schmuck, 2004; Bailey et al., 2005; Faucon et al., 2005). However, few field experiments designed to elucidate a causal relationship between neonicotinoid application and honeybee decline have been conducted (Maini et al., 2010 but see Schmuck et al., 2003; Cutler and Scott-Dupree, 2007).

Clothianidin is a member of the neonicotinoid family of insecticides. In Japan, it is frequently sprayed in rice (Oryza sativa) fields in the summer. Clothianidin is meant to control sucking bugs (Trigonotylus caelestialium, Leptocorisa chinensis, Stenotus rubrovittatus, Cletus punctiger); the most serious pests in Japanese rice fields (Watanabe and Higuchi, 2006). Many beekeepers insist that clothianidin has caused mass mortality of honeybee workers and/or long-term adverse effects on broods through insecticide residue in pollen, leading to colony collapse (Taniguchi et al., 2012). Rice flowers are in full bloom for approximately 1 week in midsummer. It is at this time that clothianidin is sprayed for pest control. Sasaki (2010) suggested that honeybees often visit rice flowers, as alternative open flowers are scarce in midsummer.

To examine whether clothianidin application to rice fields in the summer results in the collapse of honeybee colonies, I conducted an experiment in the field. Ten honeybee hives were placed around a rice field at various distances from the edge of the field. By analyzing pollen samples, I first determined whether honeybees preferably visited rice flowers when their hives were established adjacent to rice fields. Next, I examined whether honeybee colonies collapsed subsequent to the spraying of clothianidin. If the colony collapsed, the relationship between the distance from the rice field to hives and the probability of colony collapse was explored. I also examined whether the number of dead workers at each hive was related to the distance from the field or to the period of time elapsed since the insecticide was applied. Lastly, potential chronic effects due to clothianidin were also assessed by monitoring temporal changes in hive weight and the capped-brood area, for 2 months following spray application. 


\section{MATERIAL AND METHODS}

The insecticide spray experiments were performed at two adjacent experimental rice fields (36.023888N, 140.097405W, $21 \mathrm{~m}$ a.s.l.) of the National Agricultural Research Center. The rectangular fields were equal in size $(100 \mathrm{~m}$ in length, $30 \mathrm{~m}$ in width). The flowering period of one field was postponed by about 4 weeks due to a delay in transplanting rice seedlings. Therefore, I conducted the spray experiments twice during each flowering period.

The experimental design was identical in both fields, with the exception of the pollen sampling method. My main objective when sampling pollen, was to examine whether honeybees frequently visit wind-pollinated (no honey) rice flowers when their hive is located near a rice field during the blooming period. Pollen was collected by attaching pollen traps to the front of hives. The traps were equipped with a plastic board with small holes through which bees were forced to pass. In the first experiment, I tried to examine the relationship between the distance from the edge of the rice fields to the hives and bee preference for rice pollen. Pollen traps were attached to every hive. However, the pollen traps prevented almost all pollen loads collected by bees from entering their hives. Therefore, the potential effects on broods caused by the ingestion of insecticidepolluted pollen could not be evaluated when the pollen traps were attached. For this reason, pollen traps were attached to the hives for only 3 hours immediately following insecticide application (10:30 am - 13:30 pm).

For the second experiment, two additional hives were established for pollen sampling only, next to the experimental hives at 0 and $30 \mathrm{~m}$ from the edge of the rice field. These hives were established from 24 August 2010 (1 week before the second spray experiment) until 30 August 2010. The traps were set up 1 week before spraying because the peak flowering season arrived sooner than expected and the spray schedule was inflexible.

Pollen was collected daily (except on 29 August 2010) from 11:00 to $12: 00$ during the second experiment. To directly confirm honeybee visits to rice flowers, visual censuses and insect sweeps were conducted daily during the experimental period from 11:00 to 12:00. Visual censuses were performed by counting the number of honeybees visiting rice flowers during a 30-minute walk along the footpaths surrounding the experimental fields. For sweeps, an insect net (diameter of $50 \mathrm{~cm}$ ) was swept 10 times around rice flowers at 10 meter intervals along the footpath.

Approximately $1 \mathrm{~g}$ of the pollen loads was randomly selected from the whole pollen loads of each hive on each date. Samples were then divided by color, and weighed to the nearest $1 \mathrm{mg}$ by color, using an electronic scale (PB1502-S; Mettler-Toledo, Osaka, Japan). When the weight of the whole pollen loads from each hive was less than $1 \mathrm{~g}$, all of the pollen loads from the sample were processed. Two pollen loads of each color from each sample were sent to Palynosurvey Co. (http://www.palyno.co.jp/index.htm) for identification of the plant species. Samples had been stored in a freezer before weighing and dividing by color. Pollen was separated using potassium hydroxide, decomposed cellulose with acetolysis (9/1 mixture of acetic anhydride and sulfuric acid), and condensed pollen. Specimens were prepared from condensed pollen by inserting glycerol. Specimens were identified under an optical microscope (Eclipse E600; Nikon, Tokyo, Japan) according to Shimakura (1973) and Nakamura (1980). Pollen color groups with less than $100 \mathrm{mg}$ were not identified to plant taxa. These groups were excluded because I wanted to know whether honeybees primarily visit neighboring rice flowers during the blooming season. Details about the flora which honeybees visit was not of interest. However, pollen color groups with less than $100 \mathrm{mg}$ were also used for the calculation of the percentage of rice pollens to whole pollens collected by honeybees.

In both experiments, hives were established on the day prior to spraying. Hives were established at distances of $0(n=4), 30(n=4)$, $60(n=1)$, and $90 \mathrm{~m}(n=1)$ from the edge of the rice fields. The experimental hives were transferred to an experimental bee field at the National Institute of Livestock and Grassland Science $(36.020555 \mathrm{~N}, 140.140 .120555 \mathrm{~W}$, $22 \mathrm{~m}$ a.s.l.) 1 week later, after the full blooming season of 0 . sativa was complete. 
Following the customary procedure for controlling sucking rice bugs, $250 \mathrm{~L}$ of a clothianidin solution ([E]-1-[2-chloro-1,3-thiazol-5ylmethyl]-3-methyl- 2-nitroguanidine; with the commercial name of Dantotsu; $20 \%$ clothianidin; Sumitomokagaku, Tokyo, Japan) was sprayed after being diluted 5000 times with water. Clothianidin was used in the experiment because this insecticide is commonly used in Japanese rice fields to control sucking bugs, and because it is believed to have a strong adverse effect on honeybee colonies (Taniguchi et al., 2012). Clothianidin spraying was conducted once at each field on 2 and 31 August 2010, respectively. For 1 week after spraying, the mortality of honeybee workers was estimated daily by counting the number of dead adults on a $1 \times 1-\mathrm{m}$ white sheet placed on the ground that extended out from each hive entrance. The most obvious sign of pesticide damage is the presence of large numbers of dead workers piled up in front of the hive entrance (Akratanakul, 1987). This method provides an inexpensive, noninvasive method for assessing bee mortality (Cutler and ScottDupree, 2007). For the second experiment, one hive placed at $60 \mathrm{~m}$ from the edge of field was excluded from the mortality analysis because insecticide was sprayed in a nearby soybean field that was the closest field to this hive.

To examine the long-term effects of clothianidin on honeybee colonies, experimental hives were weighed using a platform scale (HW-60KGL; A\&D Engineering, Osaka, Japan). The capped-brood area was estimated weekly for 2 months after spraying, following Yoshiyama et al. (2011). The proportion of the capped-brood area was estimated using the following procedure: photos were taken of both sides of every honeybee hive frame, ImageJ software (available: http:// rsbweb.nih.gov/ij/) and the "LarvaeArea" plug-in (Available: http://lbm.ab.a.u-tokyo.ac.jp/ iwata/ software/larvae) was downloaded. The area of capped broods was colored in on the frames using PC drawing software. Then the file was reopened in Imagej. The frame area was selected, and "LarvaeArea" was selected from the plug-in menu. Details of the method used to estimate the capped-brood area have been provided by Yoshiyama et al. (2011). Repeated- measure frequency data are difficult to subject to statistical analysis. For this reason, I evaluated the capped-brood area, not the proportion of the capped-brood area, by multiplying the estimated proportion of the capped-brood area by $6500 \mathrm{~cm}^{2}$, which corresponded to the total surface area of hive frames within a given hive (20 × $32.5 \mathrm{~cm}$ [height $\times$ length] $\times 5$ frames $\times 2$ [front and back of hive]). The estimated areas of the capped broods for the front and back sides of the five frames within a hive, on a given date, were combined into a single measurement. This was done because I was not interested in variation within hives.

\section{Statistical analyses}

I used a generalized linear mixed model (GLMM) (Wolfinger and O'Connell, 1993) for all analyses. For analyzing the relationship between the number of dead worker bees and either the distance from the edge of the field or the post-spray period (days), the response variable was the number of dead workers, assuming a Poisson distribution. The explanatory variables were distance, and the post-spray period as fixed effects, and hive identity as a random effect. For analyzing the estimated capped-brood area or hive weight, the response variable was the estimated capped-brood area or hive weight. The response variables followed a normal distribution. The explanatory variables were the distance, date, and their interaction as fixed effects, and hive identity as a random effect for both analyses. The effects of date and the interaction between date and distance on estimated capped-brood area and hive weight, were analyzed using two analytical models. One model included three fixed effects (date, distance, and their interaction), and one random effect (hive identity). The other model included distance and one of two fixed effects (date or the interaction between date and distance), and hive identity as a random effect. A likelihood ratio test between the two models was used to determine the significance of the effects (date and interaction). Data for the first and second experiments were always analyzed separately. All analyses were conducted using $R$ version 2.11.1 (R Development Core Team, 2010). 


\section{RESULTS}

Most of the results from the first and second experiments were similar. Pollen analyses for the first and second experiments indicated that more than half of the hives' bees (5/9 for the first experiment [no pollen was trapped in one hive in the first experiment] and 7/10 for the second experiment) primarily visited rice flowers when hives were established adjacent to rice fields during the flowering period (Tab. $1 \mathrm{a}, \mathrm{b})$. The proportion of rice pollen weight to the total weight of analyzed pollen varied among hives, ranging from 0 to $100 \%$ during the first experiment and from 0 to $97 \%$ for the second experiment. The volume of collected pollen also varied remarkably among hives and throughout the post-spray period (Tab. 1a, b). Both insect sweeps and 30-minute visual censuses revealed that honeybees visited rice flowers when hives were placed near rice fields (within $90 \mathrm{~m}$ from the edge of the field; Fig.1, 2).

The number of dead workers on a $1 \times 1$-m white sheet in front of the hive entrance was signifi- cantly related to the length of the post-spray period (days) in both the first and second experiments (Tab. 2, Fig. 3). The majority of dead workers, though, were observed 1 day after spraying with clothianidin. Subsequently, the number of dead workers did not exceed 10 (Fig. 3). In contrast, neither the distance from the hive to the edge of the rice field nor the interaction between distance and the post-spray period significantly affected the number of dead workers in either experiment (Tab. 2, Fig. 4).

Significant relationships between hive weight and distance were not detected in either experiment (estimated coefficient \pm standard deviation: $-0.0067 \pm 0.027, P=0.85$ for the first experiment; $-0.027 \pm 0.017, P=0.15$ for the second experiment; Fig. 5). Hive weight was significantly affected by date in the first experiment $\left(\chi^{2}=19.29, \mathrm{df}=9, \mathrm{P}=0.02\right.$; Fig. 5) and marginally affected by date in the second experiment $\left(\chi^{2}=16.37, \mathrm{df}=9\right.$, $P=0.06$; Fig. 5). The interaction between date and distance did not significantly affect hive weight in either experiment (first experiment:

Table 1.

Results of the palynological analyses of pollen loads collected from pollen traps attached to the front of hive entrances for the a) first (August) and b) second (September) spray experiments a)

\begin{tabular}{|c|c|c|c|c|c|c|c|c|}
\hline \multirow{3}{*}{$\begin{array}{l}\text { Distance } \\
\text { (m) }\end{array}$} & \multirow{3}{*}{$\begin{array}{l}\text { Total } \\
\text { weight } \\
\text { of } \\
\text { whole } \\
\text { pollen } \\
\text { loads (g) }\end{array}$} & \multirow{3}{*}{$\begin{array}{l}\text { Weight } \\
\text { of } \\
\text { sample } \\
\text { pollen } \\
\text { loads } \\
\text { (g) } \\
\end{array}$} & \multicolumn{6}{|c|}{ Weight of sample pollens } \\
\hline & & & \multicolumn{6}{|c|}{ Plant taxa } \\
\hline & & & Oгуzа & Poaceae* & Lagerstroemia & Benincasa & Nelumbo & Unidentified \\
\hline 0 & 11.45 & 0.95 & & $\begin{array}{l}0.70 \\
(73)\end{array}$ & & & & $0.25(27)$ \\
\hline 0 & 3.4 & 0.35 & $0.15(43)$ & & $0.076(22)$ & $0.077(22)$ & & $0.04(13)$ \\
\hline 0 & 3.28 & 0.70 & $0.67(96)$ & & & & & $0.03(4)$ \\
\hline 0 & 12.2 & 1.00 & & $0.92(92)$ & & & & $0.08(8)$ \\
\hline 30 & 32.26 & 1.02 & $0.77(76)$ & & $0.21(21)$ & & & $0.04(3)$ \\
\hline 30 & 31.35 & 0.83 & $0.45(54)$ & & & & $0.24(29)$ & $0.14(17)$ \\
\hline 30 & 0.2 & 0.06 & $\begin{array}{c}0.0085 \\
(13)\end{array}$ & & 0.056 (87) & & & \\
\hline 30 & 0 & & & & & & & \\
\hline 60 & 7.88 & 0.94 & $0.82(88)$ & & & & & $0.11(12)$ \\
\hline 90 & 1.57 & 0.93 & $\begin{array}{c}0.93 \\
(100)\end{array}$ & & & & & \\
\hline
\end{tabular}

*Unidentifiable to genus but definitely different from Oryza pollen. 
b)

Table 1. Continued

\begin{tabular}{|c|c|c|c|c|c|c|c|c|}
\hline \multirow{3}{*}{$\begin{array}{l}\text { Distance } \\
(\mathrm{m})\end{array}$} & \multirow{3}{*}{$\begin{array}{l}\text { Period } \\
\text { (days) }\end{array}$} & \multirow{3}{*}{$\begin{array}{l}\text { Total } \\
\text { weight } \\
\text { of } \\
\text { pollen } \\
\text { loads } \\
\text { (g) }\end{array}$} & \multirow{3}{*}{$\begin{array}{l}\text { Weight } \\
\text { of } \\
\text { sample } \\
\text { pollen } \\
\text { loads } \\
\text { (g) }\end{array}$} & \multicolumn{5}{|c|}{ Weight of sample pollens } \\
\hline & & & & \multicolumn{5}{|c|}{ Plant taxa } \\
\hline & & & & Oryza & Lagerstroemia & Cucurbia & Oenothera & $\begin{array}{l}\text { Unidenti- } \\
\text { fied }\end{array}$ \\
\hline 0 & 1 & 2.20 & 0.87 & & $0.47(54)$ & $0.34(39)$ & & $0.07(7)$ \\
\hline 30 & 1 & 7.36 & 1.00 & $\begin{array}{l}0.89 \\
(89)\end{array}$ & & & & $0.11(11)$ \\
\hline 0 & 2 & 2.70 & 0.87 & & & $0.63(72)$ & & $0.24(28)$ \\
\hline 30 & 2 & 0.54 & 0.48 & $\begin{array}{l}0.45 \\
(92)\end{array}$ & & & & $0.04(8)$ \\
\hline 0 & 3 & 13.21 & 0.97 & $\begin{array}{l}0.77 \\
(79)\end{array}$ & $0.13(14)$ & & & 0.07 (7) \\
\hline 30 & 3 & 0.98 & 0.64 & $\begin{array}{l}0.57 \\
(88)\end{array}$ & & & & 0.07 (12) \\
\hline 0 & 4 & 35.03 & 0.91 & $\begin{array}{l}0.77 \\
(85)\end{array}$ & & & & $0.13(15)$ \\
\hline 30 & 4 & 0.73 & 0.50 & $\begin{array}{l}0.48 \\
(97)\end{array}$ & & & & $0.02(3)$ \\
\hline 0 & 6 & 23.18 & 1.55 & & $1.13(73)$ & & $0.18(11)$ & $0.25(16)$ \\
\hline 30 & 6 & 1.75 & 0.93 & $\begin{array}{l}0.67 \\
(73)\end{array}$ & $0.20(21)$ & & & $0.06(6)$ \\
\hline
\end{tabular}

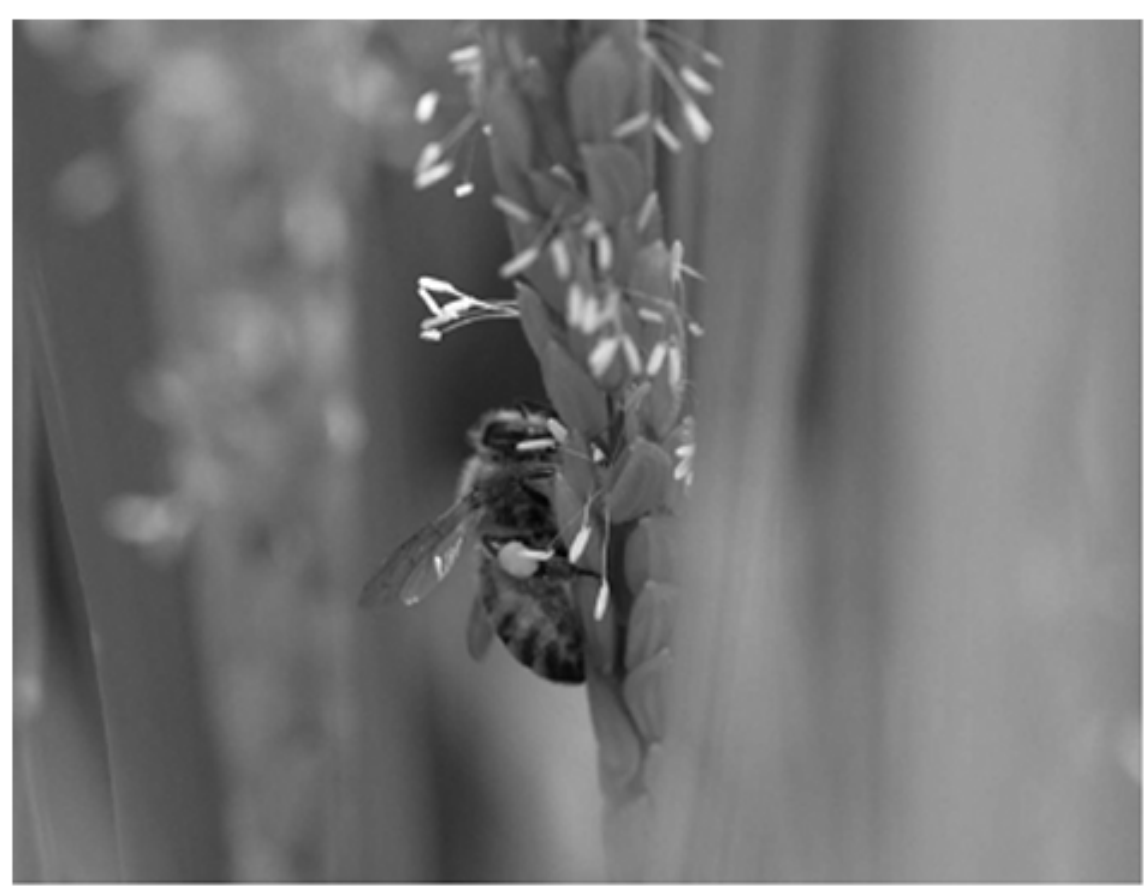

Fig. 1. Honeybee visit to and pollen collection from a rice flower (Oryza sativa). 

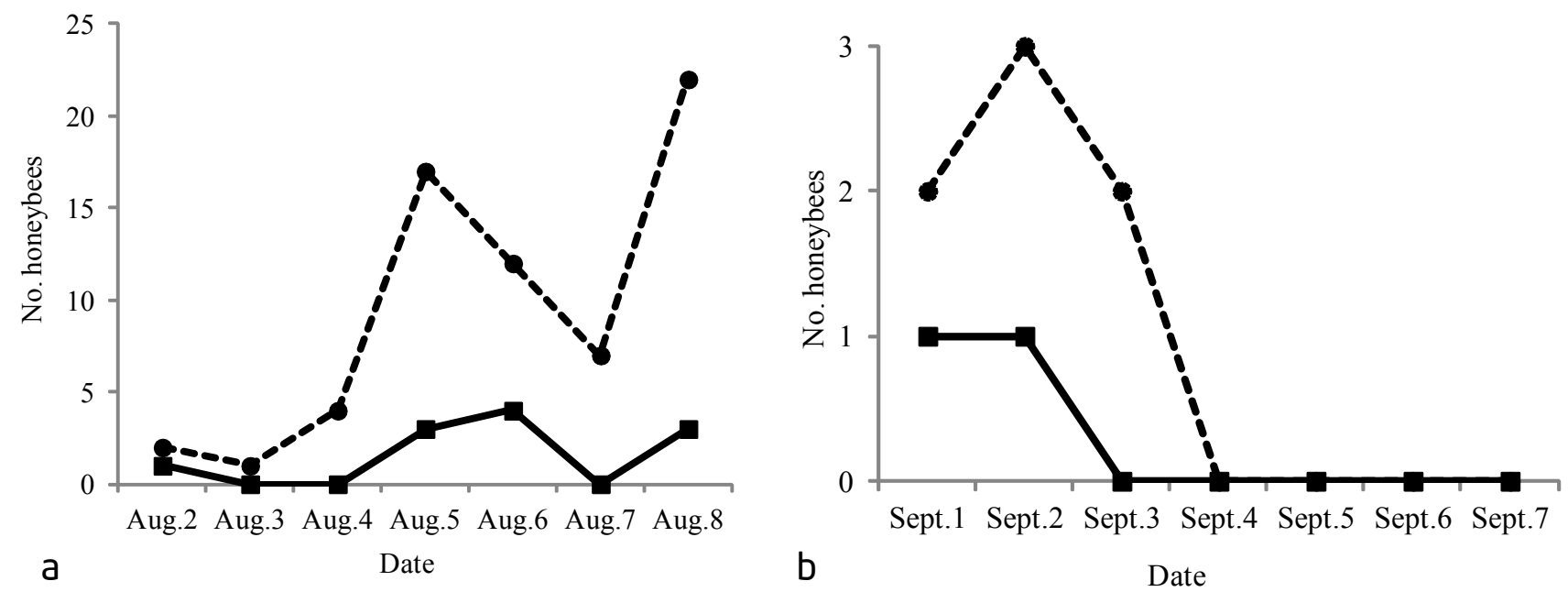

Fig. 2. Temporal changes in the number of honeybee workers observed during 30-minute visual censuses (dashed line) and insect sweeps (solid line) for the first (August; a) and second (September; b) experiments.

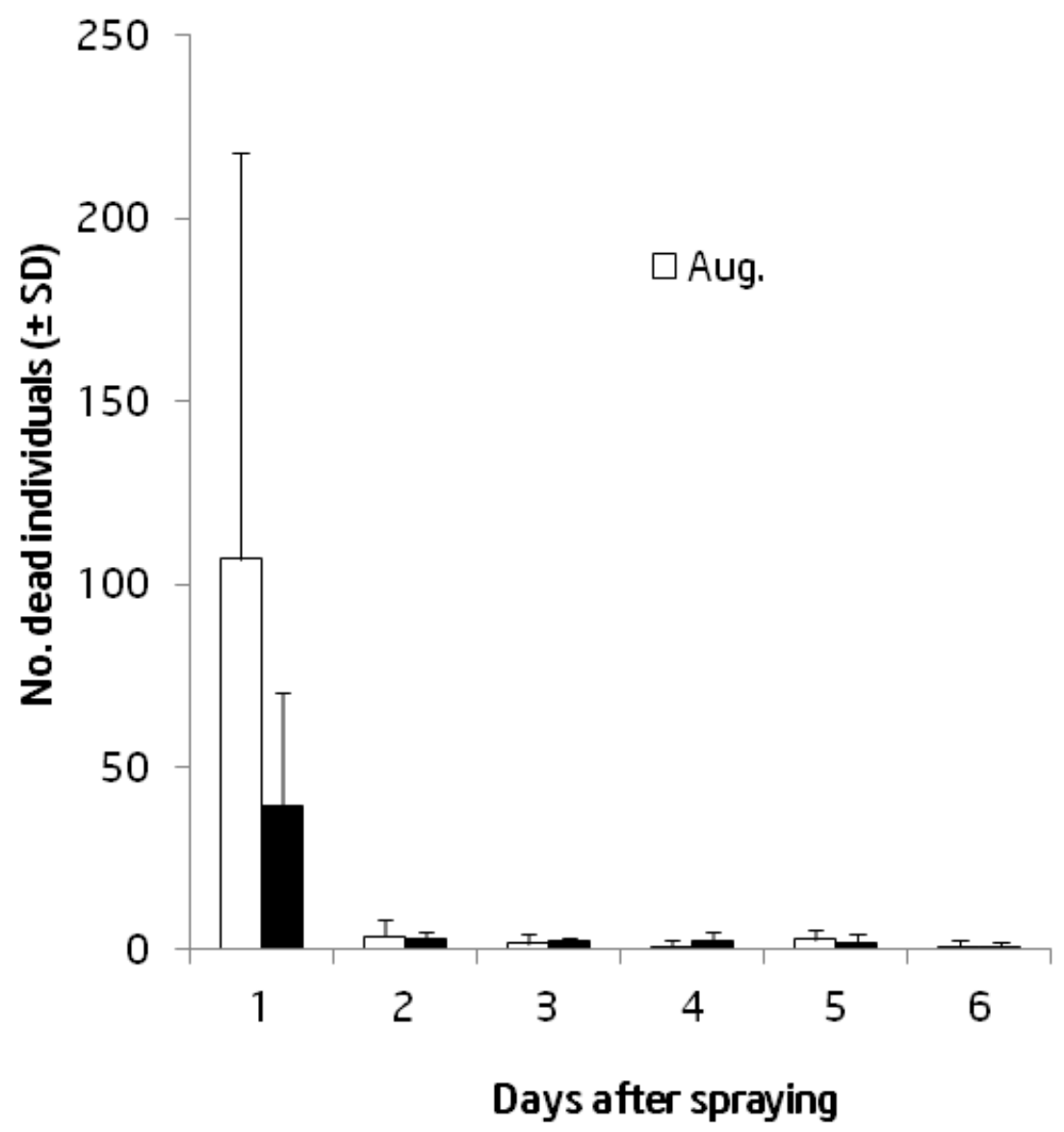

Fig. 3. Relationships between the number of dead honeybees observed on a $1 \times 1-m$ white sheet placed on the ground in front of each hive entrance and the length of the period (days) after clothianidin spraying. White and black bars represent the first (August) and second (September) experiments, respectively. Error bars denote standard deviations. 


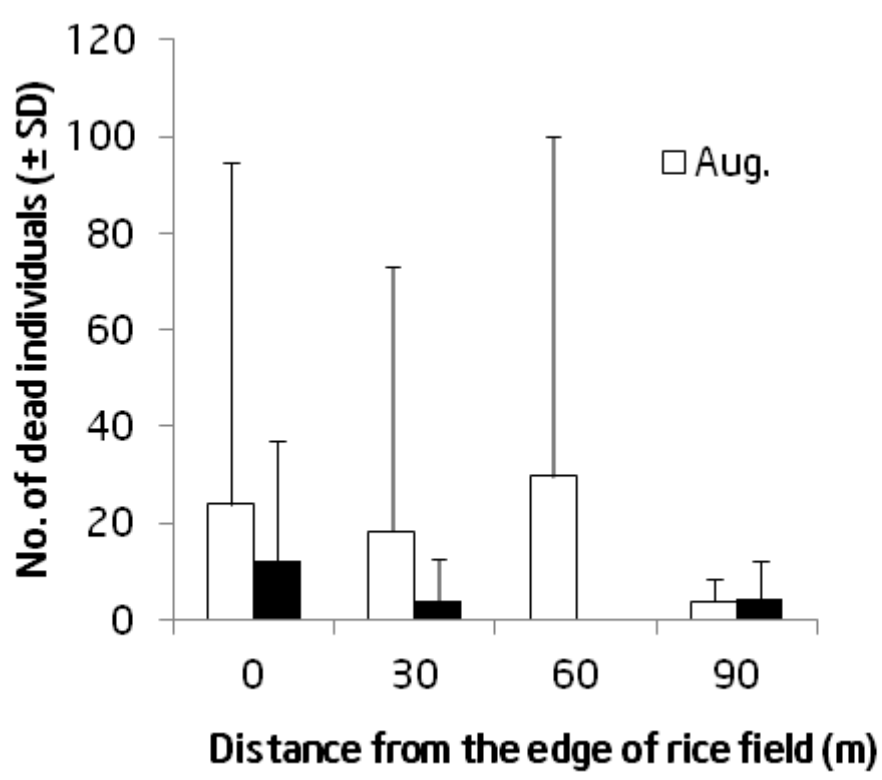

Fig. 4. Relationships between the number of dead honeybees and distance from the edge of the rice field. White and black bars represent the first (August) and second (September) experiments, respectively. Error bars denote standard deviations.

Table 2.

Results of a generalized linear mixed model (GLMM) on the effects of the distance from the edge of the rice field and length of the period (days) after spraying with neonichotinoids on the number of dead honeybee workers observed during spray experiments in the first (August) and second (September). Estimated coefficients and standard deviations (SD) for the first (August) and second (September) spray experiments.

\begin{tabular}{ccc}
\cline { 2 - 3 } & \multicolumn{2}{c}{ Coefficient \pm SD } \\
\cline { 2 - 3 } & \multicolumn{2}{c}{ Trial } \\
\cline { 2 - 3 } & First & Second \\
\hline Distance & $-0.00081 \pm 0.016$ n.s. & $-0.017 \pm 0.12$ n.s. \\
\hline Period & $-1.70 \pm 0.10^{*}$ & $-1.33 \pm 0.080^{\star}$ \\
\hline Distance*Period & $-0.0043 \pm 0.0030$ n.s. & $0.0040 \pm 0.0025$ n.s. \\
\hline
\end{tabular}

n.s. - not significant; * $-\mathrm{P}<0.0001$

$\chi^{2}=13.65, \mathrm{df}=9, \mathrm{P}=0.14$; secondexperiment: $\chi^{2}=2.04, \mathrm{df}=9, \mathrm{P}=0.99$; Fig. 5).

Distance did not significantly affect the estimated capped-brood area (estiamated coefficient \pm standard deviation: $1.74 \pm 3.80$, $P=0.73$ for the first experiment; $-1.39 \pm$ 2.91, $\mathrm{P}=0.72$ for the second experiment; Fig. 6). The effects of date and the interaction between date and distance on the capped-brood area were significant in the second experiment (date: $\chi^{2}=57.43, \mathrm{df}=9, \mathrm{P}<0.0001$; interac- tion: $\chi^{2}=25.32, \mathrm{df}=9, \mathrm{P}<0.01$; Fig. 6), but not in the first (date: $\chi^{2}=8.34$, df $=6, P=0.21$; interaction: $\chi^{2}=3.10, \mathrm{df}=6, \mathrm{P}=0.80 ;$ Fig. 6).

\section{DISCUSSION}

Pesticides applied to agricultural fields have been suggested as a primary factor contributing to declines in honeybee colonies (AllenWardell et al., 1998). In particular, clothianidin sprayed on rice fields for the control of rice bugs 


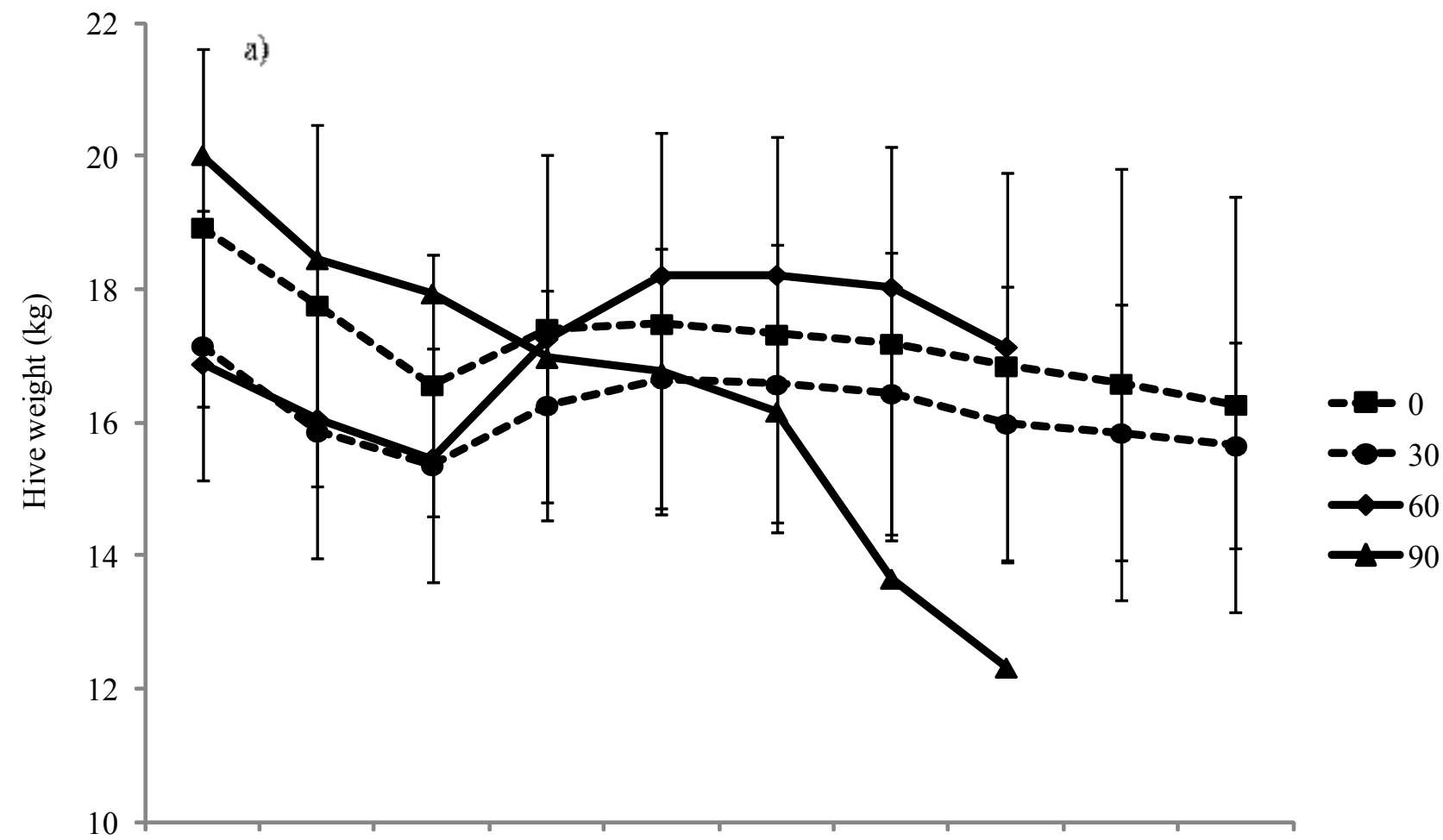

Aug. 1 Aug. 9 Aug. 16 Aug. 23 Aug. 30 Sept. 6 Sept. 13 Sept. 20 Sept. 30 Oct. 4

Date

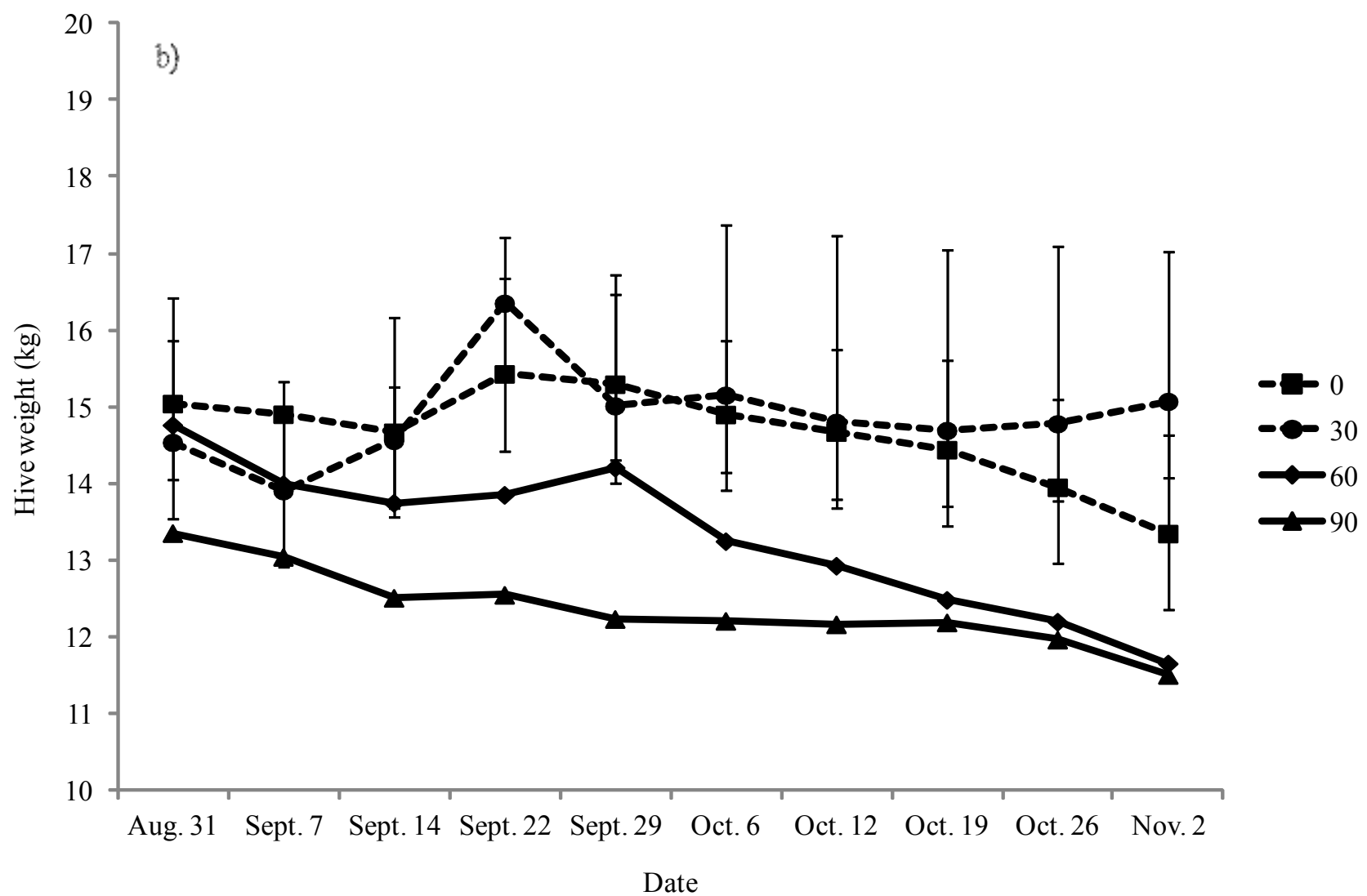

Fig. 5. Temporal changes in hive weight with distance from the edge of the rice field (square symbols and dashed line for $0 \mathrm{~m}$, circles and dashed lines for $30 \mathrm{~m}$, diamonds and solid line for $60 \mathrm{~m}$, triangles and solid line for $90 \mathrm{~m}$ ) beginning immediately before the onset of the clothianidin spray experiments until 2 months after the spray for the a) first (August) and b) second (September) experiments. Each vertical bar denotes the standard deviation. 

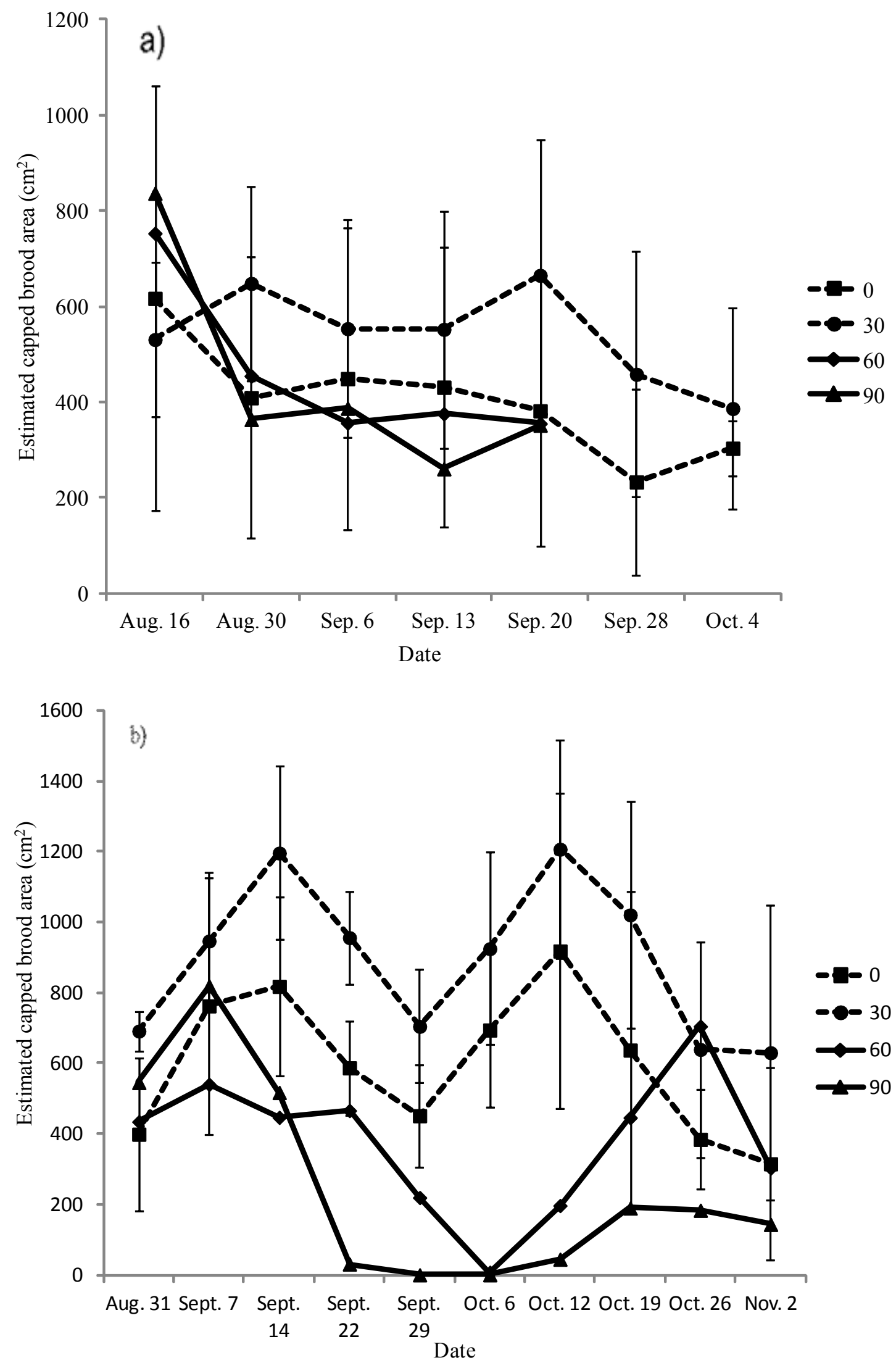

Fig. 6. Temporal changes in estimated capped-brood area with distance from the edge of the rice field (square symbols and dashed line for $0 \mathrm{~m}$, circles and dashed lines for $30 \mathrm{~m}$, diamonds and solid line for $60 \mathrm{~m}$, triangles and solid line for $90 \mathrm{~m}$ ) beginning immediately before the onset of the clothianidin spray experiments until 2 months after the spray for the a) first (August) and b) second (September) experiments. Each vertical bar denotes the standard deviation. 
in midsummer, may be related to the sudden collapse of bee colonies in Japan (Taniguchi et al., 2012). Although toxic levels $\left(L_{50}\right)$ of some neonicotinoid insecticides, including clothianidin, have been documented for honeybees (Iwasa et al., 2004), field experiments testing a cause-and-effect relationship between clothianidin spray in rice fields and honeybee colony collapse had not been conducted to date. To examine whether the application of clothianidin spray leads to the collapse of honeybee colonies, I conducted field experiments twice throughout the summer. Both experiments demonstrated that colony collapse did not occur even when 20 hives were placed very close to treated rice fields (within $90 \mathrm{~m}$ of the edge). It is important to note however, that many dead honeybee workers were observed in front of hive entrances soon after spraying. Increased mortality following the spray of insecticide has potential negative effects on the honeybee colony, but neither a rapid drop in colony weight nor capped-brood area was observed following insecticide application. It is possible that these results suggest that the high initial number of dead workers did not impose serious damage in terms of colony growth.

Because systemic insecticides confer long-lasting pest control, adverse effects on honeybees may be either delayed or chronic (Girolami et al., 2009) rather than the acute effects observed here. A number of dead workers in front of hives was frequently observed within 24 hours after the application of clothianidin spray. After the first 24 hours, however, only a small number of dead workers was observed. In terms of a lethal effect by topical dose, these results strongly suggest that the exposure level experienced by most foraging bees within 24 hours of initial exposure was below the lethal threshold. Though it is true that adverse effects do not completely disappear thereafter. To better determine the duration of the adverse effects of clothianidin spray on honeybees in terms of topical dose, future studies are needed to examine the relationship between the topical dose experienced by bees foraging in rice fields, and the length of the post-spray period.
The distance from the edge of the rice fields did not significantly affect the number of dead workers. The spatial scale examined in the present experiment was narrow (from 0 to $90 \mathrm{~m}$ ); thus, larger spatial scales should be considered as well. However, throughout the examined range, the effect of distance from the rice field on the number of dead workers was clearly negligible. Hives placed directly adjacent to the edge of the field should have received more direct exposure of clothianidin than those placed at farther distances (60 or $90 \mathrm{~m}$ ). There was a lack of a significant relationship between distance and the number of dead workers. Such results suggest that exposure while visiting rice flowers, rather than the direct exposure of hives, may be primarily responsible for the increased mortality of honeybee workers.

Although the preference of honeybees for rice flowers is not particularly high (Sasaki, 2010) since the flowers do not produce nectar, the visitation rates of honeybees to rice flowers when hives are located near rice fields has remained unclear. The pollen analysis done in this experiment revealed that more than half of the hives established within $90 \mathrm{~m}$ of the rice field during blooming preferentially collected rice flower pollen. Unfortunately, identification of the pollen loads to the species level was impossible. However, pollen identified to the genus Oryza can be reasonably considered to originate from Oryza sativa because bees were frequently observed collecting pollen on rice flowers, and because 0 . sativa was by far the most abundant Oryza plant flowering in the vicinity. The ratio of preference to rice flower by honeybees remains unclear because of the relatively small hive numbers used in the pollen sampling. However, there is no doubt that honeybees frequently visit wind-pollinated rice flowers when their hives are located in the vicinity of a rice field. Visual censuses and insect sweeps also confirmed that honeybees visited and collected pollen from rice flowers. In addition, the number of bees visiting rice flowers tended to increase during the experimental period. This information combined with the fact that the increased mortality of honeybee workers only occurred within 24 hours of clothianidin appli- 
cation, suggests the following hypothesis: the number of dead workers due to clothianidin spray depends on the timing of application. Clothianidin applied late in the season during the rice flowering peak would pose a more serious threat to neighboring bee colonies because of higher rates of bee foraging.

Systemic insecticides such as neonicotinoids are designed to permeate the entire plant, including nectar and pollen, and to remain within the plant in the long term (Laurent and Rathahao, 2003). Clothianidin, which is a member of the family of neonicotinoids, may also have longlasting adverse effects on honeybee broods through clothianidin-contaminated pollen remaining inside hives. To test for the long-term effects of clothianidin, hive weight, and cappedbrood area were measured for 2 months after the spraying of clothianidin. Colony collapse was not observed nor was there a remarkable drop in brood production during the experimental period. These results were similar to other field studies on the long-term effects of corn seed coated with imidacloprid on honeybee colony performance (Cutler and Scott-Dupree, 2007). Furthermore, hive distance from the rice field did not significantly affect hive weight or brood production. However, my long-term results should be interpreted with caution, as the experiment was finished by late fall and the mortality during winter was not evaluated. Pollen contaminated with clothianidin could potentially reduce the quality (e.g., longevity of wintering adults) or quantity of adult honeybees, resulting in increased winter mortality. To fully understand such long-term effects, measurements of clothianidin residue levels within collected and stored pollen as well as feeding experiments using clothianidin-contaminated pollen are required. In addition, the pollen trap prevented most of the contaminated pollen from entering the hives on the spraying date in the first experiment. This is a possible reason why colony collapse did not occur. However, neither colony collapse nor a rapid drop in brood production occurred during the second experiment, suggesting that long-term effects at the colony level rarely occur.
In the present study, I was also unable to isolate the direct effect of clothianidin spray because of the lack of a control field with no clothianidin application. However, it was successfully demonstrated that honeybee colonies placed near rice fields where clothianidin was sprayed during the flowering season, never collapsed in our study. Notably, honeybee sensitivity to pesticides strongly varies among seasons (Meled et al., 1998; Smirle and Winston, 1998), physiological conditions (Wahl and Ulm, 1983), age (Guez et al., 2001), race (Suchail et al., 2000), and even colonies (Suchail et al., 2001). Because bees forage optimally (Seeley, 1995), their foraging area and preferred plant species depend on environmental conditions, especially the quality and quantity of neighboring flowering plants. Additional studies under various environmental conditions are required to clarify the adverse effects of clothianidin sprayed in rice fields. I applied clothianidin on only one rice field in each experiment. But bees probably foraged other untreated rice fields in the neighborhood of the experimental fields because honeybees forage within 4 - $5 \mathrm{~km}$ of their hives, with a peak at approximately 2 - $3 \mathrm{~km}$. The negative effects of neonicotinoid application demonstrated in this study are probably underestimated. Future experiments are required to correctly estimate the side-effects of neonicotinoid on the honeybee.

\section{CONCLUSIONS}

This study demonstrated that: 1) honeybee workers in the hives located in neighborhood of a rice field, preferentially forage rice flowers during the flowering season; 2) many honeybee workers died in front of the hive entrance within 24 hours following the application (spray) of clothianidin; 3) after that, few dead worker were observed in front of the hive entrance; 4) neither a rapid drop in brood production nor colony collapse were detected. Neonicotinoid application within a rice field increased honeybee mortality immediately after its application, but the observed short-term effects do not always lead to collapse of a neighboring honeybee colony and long-term effects were not observed. 


\section{ACKNOWLEDGMENTS}

I would like to thank Dr. K. Kimura and Dr. M. Yoshiyama for their helpful advice about an experimental design, Mr. H. Hodoyama, Mr. S. Hoshino, Ms. K. Saito, and Mr. U. Zhu for assistance with the field experiments, Mrs. N. Takaya and Mrs. M. Iwamoto for assistance with the estimation of the capped-brood area, Mr. T. Ichiishi, Mr. M. Yamazaki, and Mr. T. Najiwara for help with the insecticide application, and the National Agricultural Research Center for permission to use its experimental rice field. This study was supported in part by Research and Development Projects for Application in Promoting New Policy of Agriculture Forestry and Fisheries (22010) from the Japanese Ministry of Agriculture, Forestry and Fisheries.

\section{REFERENCES}

Abbott V. A., Nadeau J. L., Higo H. A., Winston M. L. (2008) Lethal and sublethal effects of imidacloprid on osmia lignaria and clothianidin on Megachile rotundata (Hymenoptera : megachilidae). Journal of Economic Entomology 101: 784-796.

Aguilar R., Ashworth L., Galetto L., Aizen M. A. (2006) Plant reproductive susceptibility to habitat fragmentation: review and synthesis through a meta-analysis. Ecology Letters 9: 968-980. DOl: 10.1111/j.1461-0248.2006.00927.x

Aizen M. A., Garibaldi L. A., Cunningham S. A., Klein A. M. (2008) Long-Term Global Trends in Crop Yield and Production Reveal No Current Pollination Shortage but Increasing Pollinator Dependency. Current Biology 18: 1572-1575. DOl: 10.1016/j. cub.2008.08.066

Allen-Wardell G., Bernhardt P., Bitner R., Burquez A., Buchmann S., Cane J., Cox P. A., Dalton V., Feinsinger P., Ingram M., Inouye D., Jones C. E., Kennedy K., Kevan P., Koopowitz H., Medellin R., Medellin-Morales S., Nabhan G. P., Pavlik B., Tepedino V., Torchio P., Walker S. (1 998) The potential consequences of pollinator declines on the conservation of biodiversity and stability of food crop yields. Conservation Biology 12: 8-17. DOl:10.1 111/j.1523-1739.1998.97154.x
Akratanakul P. (1 987) Beekeeping in Asia. FAO Agricultural Services Bulletin 68/4. FAO. Rome. Italy. $112 \mathrm{pp}$.

Bailey J., Scott-Dupree C., Harris R., Tolman J., Harris B. (2005) Contact and oral toxicity to honey bees (Apis mellifera) of agents registered for use for sweet corn insect control in Ontario, Canada. Apidologie 36: 623-633. DOl: 10.1073/pnas.1232346100

Bernal J., Garrido-Bailon E., del Nozal M. J., GonzalezPorto A. V., Martin-Hernandez R., Diego J. C., Jimenez J. J., Bernal J. L., Higes M. (2010) Overview of Pesticide Residues in Stored Pollen and Their Potential Effect on Bee Colony (Apis mellifera) Losses in Spain. Journal of Economic Entomology 103: 1964-1971. DOl: 10.1603/EC10235

Biesmeijer J. C., Roberts S. P. M., Reemer M., Ohlemuller R., Edwards M., Peeters T., Schaffers A. P., Potts S. G., Kleukers R., Thomas C. D., Settele J., Kunin W. E. (2006) Parallel declines in pollinators and insect-pollinated plants in Britain and the Netherlands. Science 313: 351-354. DOl: 10.1126/science.1 127863

Chauzat M. P., Martel A. C., Zeggane S., Drajnudel P., Schurr F." Clement M. C." Ribiere-Chabert M., Aubert M., Faucon J. P. (2010) A case control study and a survey on mortalities of honey bee colonies (Apis mellifera) in France during the winter of 20056. Journal of Apicultral Research 49: 40-51. DOl: 10.3896/IBRA.1.49.1.06

Chauzat M. P., Carpentier P., Martel A. C., Bougeard S., Cougoule N., Porta P., Lachaize J., Madec F., Aubert M., Faucon J. P. (2009) Influence of Pesticide Residues on Honey Bee (Hymenoptera: Apidae) Colony Health in France. Environmental Entomology 38: 514-523. DOl: 10.1603/022.038.0302

Cresswell J. E. (2011) A meta-analysis of experiments testing the effects of a neonicotinoid insecticide (imidacloprid) on honey bees. Ecotoxicology 20: 149-157. DOl: 10.1007/s10646-010-0566-0

Cutler G. C., Scott-Dupree C. D. (2007) Exposure to clothianidin seed-treated canola has no long-term impact on honey bees. Journal of Economic Entomology 100: 765-772. DOl: 


\subsection{3/0022-0493(2007)100[765:ETCSCH]2.0 $\mathrm{CO} ; 2$}

Elbert A., Haas M., Springer B., Thielert W., Nauen R. (2008) Applied aspects of neonicotinoid uses in crop protection. Pest Management Science 64: 1099-1 105. DOl: 10.1002/ps.1616

Faucon J. P., Aurieres C., Drajnudel P., Mathieu L., Ribiere M., Martel A. C., Zeggane S., Chauzat M. P., Aubert M. F. A. (2005) Experimental study on the toxicity of imidacloprid given in syrup to honey bee (Apis mellifera) colonies. Pest Management Science 61: 111-125. DOl: 10.1002/ps.957

Girolami V., Mazzon L., Squartini A., Mori N., Marzaro M., Di Bernardo A., Greatti M., Giorio C., Tapparo A. (2009) Translocation of Neonicotinoid Insecticides From Coated Seeds to Seedling Guttation Drops: A Novel Way of Intoxication for Bees. Journal of Economic Entomology 102: 1808-1815. DOl: 10.1603/029.102.0511

Goulson D., Lye G. C., Darvill B. (2008) Decline and conservation of bumble bees. Annual Review of Entomology 53: 191-208. DOl: 10.1146/annurev. ento.53.103106.093454

Guez D., Suchail S., Gauthier M., Maleszka R., Belzunces L. P. (2001) Contrasting effects of imidacloprid on habituation in 7- and 8-day-old honeybees (Apis mellifera). Neurobiology of Learning and Memory 76: 183-1 91. DOl: 10.1006/nIme.2000.3995

Iwasa T., Motoyama N., Ambrose J. T., Roe R. M. (2004) Mechanism for the differential toxicity of neonicotinoid insecticides in the honey bee, Apis mellifera. Crop Protection 23: 371-378. DOl: 10.1016//.cropro.2003.08.018

Laurent F. M. , Rathahao E. (2003) Distribution of C-14 imidacloprid in sunflowers (Helianthus annuus L.) following seed treatment. Journal of Agricultural and Food Chemistry 51: 8005-801 0. D0l: 10.1021/ jf034310n

Maini S., Medrzycki P., Porrini C. (2010) The puzzle of honey bee losses: a brief review. Bulletin of Insectology 63: 153-160.
Meled M., Thrasyvoulou A., Belzunces L. P. (1998) Seasonal variations in susceptibility of Apis mellifera to the synergistic action of prochloraz and deltamethrin. Environmental Toxicology and Chemistry 17: 2517-2520. DOl: 10.1002/etc.5620171220

Mullin C. A., Frazier M., Frazier f. L., Ashcraft S., Simonds R., vanEngelsdorp D., Pettis.. S. (2010) High Levels of Miticides and Agrochemicals in North American Apiaries: Implications for Honey Bee Health. PLoS One 5(3): e9754. DOl: 10.1371/journal.pone.0009754

Nakamura J. (1980) Characteristics of Japanese pollen I II. Special publications from the Osaka Museum of Natural History. ver.12 14, Japan. pp. 91 (in Japanese).

Nguyen B. K., Saegerman C., Pirard C., Mignon J." Widart J., Tuirionet B., Verheggen F. J., Berkvens D., De Pauw E., Haubruge E. (2009) Does Imidacloprid Seed-Treated Maize Have an Impact on Honey Bee Mortality? Journal of Economic Entomology 102(2): 613-623

Oldroyd B. P. (2007) What's killing American honey Bees? Plos Biology 5: 1195-1199. DOl: 10.1371/ journal.pbio.0050168

Orantes-Bermejo F. J., Pajuelo A. G., Megias M. M., Fernandez-Pinar C. T. (2010) Pesticide residues in beeswax and beebread samples collected from honey bee colonies (Apis mellifera L.) in Spain. Possible implications for bee losses. Journal of Apicultural Research 49: 243-250. DOl: 10.3896/IBRA.1.49.3.03

Pettis J. S., Delaplane K. S. (2010) Coordinated responses to honey bee decline in the USA. Apidologie 41: 256-263. DOl: 10.1051/apido/2010013

Potts S. G., Biesmeijer J. C., Kremen C., Neumann P." Schweiger O., Kunin W. E. (2010) Global pollinator declines: trends, impacts and drivers. Trends in Ecology and Evolution 25: 345-353. 10.1016/j. tree.2010.01.007

R Development Core Team (2010) R: a language and environment for statistical computing. R foundation for statistical computing. Vienna. Austria. Avaliable at: http://www.R-project.org 
Ricketts T. H., Regetz J., Steffan-Dewenter I., Cunningham S. A., Kremen C., Bogdanski A., GemmillHerren B., Greenleaf S. S., Klein A. M., Mayfield M. M., Morandin L. A., Ochieng A., Viana B. F. (2008) - Landscape effects on crop pollination services: are there general patterns? Ecology Letters 11: 499-515. DOl: $10.1111 / j .1461-0248.2008 .01157 . x$

Rortais A., Arnold G., Halm M. P.", Touffet-Briens F. (2005) Modes of honeybees exposure to systemic insecticides: estimated amounts of contaminated pollen and nectar consumed by different categories of bees. Apidologie 36: 71-83. DOl: 10.1051/ apido:2004071

Sasaki M. (2010) Bee's Eye View of Flowering Plants: Nectar- and Pollen-source Plants and Related Honeybee Products. Kaiyusha. Tokyo. Japan. 413 pp.

Schmuck R. (2004) Effects of a chronic dietary exposure of the honeybee Apis mellifera (Hymenoptera : Apidae) to imidacloprid. Archives of Environmental Contamination and Toxicology 47: 471-478. DOl: 10.1007/s00244-004-3057-6

Schmuck R., Stadler T., Schmidt H. W. (2003) Field relevance of a synergistic effect observed in the laboratory between an EBI fungicide and a chloronicotinyl insecticide in the honeybee (Apis mellifera L., Hymenoptera). Pest Management Science 59, 279 286.

Schmuck R., Schoning R. Stork A., Schramel 0 . (2001) Risk posed to honeybees (Apis mellifera L. Hymenoptera) by an imidacloprid seed dressing of sunflowers. Pest Management Science 57: 225 238.

Seeley T. (1995) The Wisdom of the Hive: The Social Physiology of Honey Bee Colonies. Harvard University Press. Harvard. USA. 318 pp.

Shimakura M. (1973) Pollen morphology of Japanese plants. Special publications from the Osaka Museum of Natural History. ver. 5, Japan. 60 pp. (in Japanese). Smirle M. J., Winston M. L. (1987) Intercolony variation pesticide detoxification by the honey-bee (Hymenoptera, Apidae). Journal of Economic Entomology 80: 5-8.
Suchail S., Guez D., Belzunces L. P. (2000) Characteristics of imidacloprid toxicity in two Apis melliferasubspecies. Environmental Toxicology and Chemistry 19: 1901-1905. DOl: 10.1002/etc.5620190726

Suchail S., Guez D., Belzunces L. P. (2001) Discrepancy between acute and chronic toxicity induced by imidacloprid and its metabolites in Apis mellifera. Environmental Toxicology and Chemistry 20: 24822486.

Taniguchi T., Kita Y., Matsumoto T., Kimura K. (2012) Honeybee colony loss during 2008-2010 caused by pesticide application in Japan. Journal of Apiculture 27(1): 15-27.

Tasei J. N., Ripault G., Rivault E. (2001) Hazards of imidacloprid seed coating to Bombus terrestris (Hymenoptera : Apidae) when applied to sunflower. Journal of Economic Entomology 94: 623-627. DOl: 10.1603/0022-0493-94.3.623

VanEngelsdorp D., Meixner M. D. (2010) A historical review of managed honey bee populations in Europe and the United States and the factors that may affect them. Journal of Invertebrate Pathology 103: S80-S95. DOl: 10.1016/j.jip.2009.06.011

Wahl O., Ulm K. (1983) Influence of pollen feeding and physiological condition on pesticide sensitivity of the honey bee Apis mellifera carnica. Oecologia 59: 106-128.

Watanabe M. E. (1994) Pollination worries rise as honey-bees decline. Science 265: 11 70-1 1 70. DOl: 10.1126/science.265.5176.1170

Watanabe T., Higuchi H. (2006) Recent occurrence and problem of rice bugs. Plant Protection 60: 201 203 (in Japanese with English summary).

Wolfinger R., Oconnell M. (1993) Generalized linerar mixed models - a psedo-likelihood approach. Journal of Statistical Computation and Simulation 48: 233243.

Yoshiyama M., Kimura K., Saitoh K., Iwata H. (201 1) Measuring colony development in honey bees by simple digital image analysis. Journal of Apicultural Research 50: 170-172. DOl: 10.3896/ IBRA. 1.52.1.03 